\title{
Predation on massive corals: are devastating population outbreaks of Acanthaster planci novel events?
}

\author{
Ann M. Cameron, R. Endean, L. M. DeVantier* \\ Department of Zoology, University of Queensland, Brisbane, 4072 Australia
}

\begin{abstract}
Coral communities on many reefs of the central third of Australia's Great Barrier Reef have been subject to major damage by population outbreaks of the crown-of-thorns starfish Acanthaster planci twice since the 1960's. The interval between outbreaks on individual reefs was approximately $15 \mathrm{yr}$. This study compares size and damage frequency distributions of major taxa of scleractinian reef corals of massive morphology on 2 sets of 6 reefs of this region. One set of reefs had experienced major population outbreaks of $A$. planci, one set had not. All major reef types found in the area were represented in the sets which spanned 3 degrees of latitude. On both reef sets, representatives of the families Faviidae, Poritidae and Mussidae comprised ca $90 \%$ of the massive corals present. However, the relative proportions of these taxa differed markedly between the 2 reef sets, with members of the Faviidae predominant on non-outbreak reefs and members of the Poritidae predominant on outbreakaffected reefs. Massive coral assemblages on outbreak reefs possessed only $1 / 3$ the colonies on unaffected reefs and approximately half the surviving corals on the outbreak reefs exhibited damage of $>1 / 3$ their colony surface areas. Few large (old) colonies occurred on the outbreak reefs, whereas such large corals were common on unaffected reefs. As most massive corals are slow-growing, long-lived and have lower rates of recruitment than corals of other morphology, continuing starfish reinfestation coincident with reestablishment of a coral cover by the faster-growing, more opportunistic corals will not allow sufficient time for recovery of the massive coral assemblages. They will be replaced by algae and non-massive coral assemblages in the intervals between outbreaks. The recent devastating outbreaks appear to be abnormal perturbations coincident with large-scale human activities on the Great Barrier Reef, rather than integral features of reef ecology.
\end{abstract}

\section{INTRODUCTION}

Predation on corals by the crown-of-thorns starfish Acanthaster planci (Linné, 1758) has caused major damage to coral communities of the Great Barrier Reef (GBR) and elsewhere in the Indo-West Pacific region since the 1950's (Endean \& Cameron 1985, Moran 1986, Moran et al. 1988, Endean \& Cameron 1990). Large populations of the starfish kill entire colonies of most coral species despite individual preferences for different coral types in some circumstances (Moran 1986). The first recorded outbreaks of A. planci on the GBR occurred in the 1960's and embraced reefs in the

- Present address: Australian Institute of Marine Science, PMB 3, Townsville MC, Queensland, 4810 Australia central third of the ecosystem (Endean 1973). Following predation of the majority of a reef's corals, most of the starfish disappeared. Within 10 to 15 yr rapidlygrowing branching and plate-like corals had reestablished an extensive coral cover on parts of many reefs (Endean \& Cameron 1985). Formation of such a coral cover has been studied at several reefs of the GBR (Endean 1976) and particularly at Green Island Reef and John Brewer Reef (Pearson 1981, Done 1985, Fisk et al. 1989).

Many reefs of the central GBR experienced a second outbreak during the 1980's (Endean \& Cameron 1985, Moran 1986). Whether such population outbreaks of Acanthaster planci are a contemporary phenomenon or are part of an ecological pattern that has persisted for thousands of years on the GBR is a contentious issue 
(Moran et al. 1986, Moran \& Bradbury 1989, Walbran et al. 1989, Keesing et al. in press). Of particular significance for resolution of the controversy concerning the novelty or otherwise of the starfish outbreaks is predation on corals of massive growth form (Cameron \& Endean 1985, Endean \& Cameron 1985, Done 1987. 1988, Endean et al. 1989, Cameron et al. in press). In contrast with rapidly-growing encrusting, branching and plate-like corals which are susceptible to many forms of perturbation affecting coral reefs and which have high turnover rates, the slow-growing massive corals are resilient to normal perturbations that occur on coral reefs, and they are typically long-lived. Many have longevities of the order of centuries (Nozaki et al. 1978, Druffel 1982, Isdale 1984, Potts et al. 1985). At least 100 of the ca 330 scleractinian species recorded from the GBR exhibit massive morphology. They represent 30 genera of the 9 families Poritidae, Faviidae, Mussidae, Oculinidae, Agariciidae, Caryophylliidae, Merulinidae, Acroporidae and Siderastreidae (Veron 1986).

The idea that massive corals are primarily responsible for determining the basic structure of complex coral communities was proposed by Cameron \& Endean (1985) and Endean \& Cameron (1990). The long-term nature of the process of recovery of coral communities from catastrophic destruction was emphasized by these authors, who noted that for complete recovery of a complex coral community from extensive damage caused by an Acanthaster planci outbreak the massive corals must attain population size structures comparable with those existing before the $A$. planci outbreak. Decades to centuries are required for this to occur because of the low levels of recruitment (Endean et al. 1989, Fisk \& Harriott 1990, Cameron et al. in press) and low growth rates (Buddemeir \& Kinzie 1976 , Babcock 1989, pers. obs.) of the majority of massive corals. Thus massive coral communities provide a convenient window through which to view the effect on coral reefs of successive $A$. planci outbreaks separated by intervals of the order of 10 to $15 \mathrm{yr}$, the observed intervals between the only documented $A$. planci out breaks on reefs of the GBR.

Provided that an adequate pool of propagules is available and environmental conditions remain favourable for coral settlement and growth, it is probable that restoration of a cover of fast-growing opportunistic corals will continue to occur in the face of repeated Acanthaster planci outbreaks. Indeed, the presence of an extensive coral cover is obviously a prerequisite for an A. planci outbreak. In contrast, it is doubtful whether populations of the slow-growing and persistent massive corals can replace their losses in the face of repeated destruction by the crown-of-thorns starfish (Cameron \& Endean 1985, Endean \& Cameron 1985). It is a prime purpose of this study to determine whether marked changes occur in the structure of massive coral communities after A. planci outbreaks.

Because of difficulties experienced when attempts are made to attribute damage to coral colonies on a particular reef unequivocally to Acanthaster planci predation, the study was designed to reveal whether numbers of massive coral colonies on reefs affected by A. planci outbreaks in recent years were markedly depleted when compared with numbers of massive coral colonies on nearby reefs that were not affected by A. planci outbreaks. If impoverishment of the massive coral assemblages occurs during outbreaks, differences in the levels of damage, in size (age) structures and possibly the relative abundances of different taxa of massive corals represented in the two reef sets should become apparent. This study sought to detect such differences.

Done (1987) modelled recovery of a mixed species assemblage of massive corals of the genus Porites at John Brewer Reef. By using different scenarios based on life history parameters (including recruitment rates, extent of destruction of different size classes, numbers of remnants, survivorship and growth rates) he made prognoses about the recovery of Porites spp. communities in the face of repeated Acanthaster planci outbreaks. These prognoses ranged from the communities holding their ground to local extinction. However, Endean et al. (1989) noted that Porites spp. appeared to be exceptional among massive coral taxa as far as resistance to $A$. planci predation, and hence recovery after $A$. planci outbreaks was concerned. Although colonies of Porites can be killed by $A$. planci (Done 1988, Done et al. 1989), they are frequently protected from total predation by the presence of inquiline worms and scallops (DeVantier et al. 1986, DeVantier \& Endean 1988). The data we obtained for massive corals other than Porites spp. on several reefs led to the conclusion that massive coral assemblages could not recover if $A$. planci outbreaks continued to recur at ca 15 yr intervals (Endean et al. 1989). In view of the importance of establishing the generality of this conclusion for the management of coral reefs, it was decided to extend our earlier studies to embrace additional reefs so that coral communities on reefs of all major types and subjected to a variety of environmental factors in the area affected by $A$. planci outbreaks were examined. Alsa, in view of the resistance exhibited by Porites spp. it was decided to take into account possible differences in resistance to $A$. planci predation exhibited by different taxa by examining all the principal taxa of massive corals encountered during surveys of these reefs. A comprehensive database on which to make prognoses about recovery of massive coral assemblages in the central region of the GBR after $A$ planci outbreaks should then be available. 


\section{METHODS}

Reefs of all major types ranging from inner shelf fringing reefs to outer shelf platform reefs in the central region of the GBR have been affected by Acanthaster planci outbreaks so a variety of reef types was included in the present study (Table 1). Different environmental conditions - including synthetic chemicals in run-off from the Queensland mainland (Endean 1976) - to which different reefs are subjected were thereby taken into account.

Data on colony size and degree of damage (partial mortality) were collected according to the protocol described earlier (Endean et al. 1989) for every massive coral present in transects on the reefs selected for study (Table 1). Thus manta tow surveys on 12 reefs of the central GBR were conducted to locate living and/or remnant assemblages of massive corals (Table 1). Six of the reefs had been affected by major population outbreaks of Acanthaster planci and 6 were unaffected. On each reef, at least 3 belt transects each of $300 \mathrm{~m}^{2}$ (30 $\mathrm{m}$ along-slope by $10 \mathrm{~m}$ down-slope) were situated in each region using plastic tapes, at randomly selected distances from the anchoring position. Additional transects, in groups of 3 , were examined on some reefs. Logistic restraints precluded a completely balanced sampling design. Transects were positioned on the reef slope from ca 3 to $10 \mathrm{~m}$ below crest. Each transect was searched systematically by SCUBA. Each massive coral colony present (representing most massive species known from the GBR) was recorded if at least half of the colony lay within the transect. The maximum diameter (maximum horizontal dimension) of each colony was measured to the nearest $0.5 \mathrm{~cm}$, and it was assigned to one of 3 size classes ( 1 to $10 \mathrm{~cm}$ diameter; 11 to $50 \mathrm{~cm}$ diameter; $>50 \mathrm{~cm}$ diameter). Counts of very small colonies are probably conservative although every effort was made to census all colonies present. The surface of each colony was inspected so that it could be assigned to one of 3 damage classes: intact or $<1 / 3$ dead surface; $1 / 3$ to $2 / 3$ dead; $>2 / 3$ dead. Counts of totally killed colonies are probably conservative because of the difficulty in detecting those that were overgrown by algae, soft and hard corals, zoanthids and encrusting sponges.

The data set was analysed at both generic and family levels. All comparisons between the 2 reef sets were made using the Wilcoxon Rank Sum test based on the mean abundance of colonies per reef (Lehmann 1975). The test compares differences between the 2 reef sets relative to inter-reef variability within the sets. Significance levels were determined from precise 2-tailed probabilities. The presence of ties makes the test conservative.

\section{RESULTS}

On both reef sets the families Faviidae, Mussidae and Poritidae comprised ca $90 \%$ of the colonies present. On reefs unaffected by starfish outbreaks, poritid corals comprised $34 \%$ of the total assemblage $130 \%$ for

Table 1. Details of each reef surveyed including name, location, reef type, year of last major Acanthaster planci outbreak (if any), date of survey, number of $300 \mathrm{~m}^{2}$ transects and total area surveyed. Reef types are Inner Shelf Platform (ISP), Mid-shelf Platform (MSP), Outer Shelf Platform (OSP), Inner Shelf Fringing (ISF). Transects were located randomly within regions with living or remnant assemblages of massive corals

\begin{tabular}{|c|c|c|c|c|c|c|c|}
\hline Reef & Lat. S. & Long. E & $\begin{array}{l}\text { Reef } \\
\text { Type }\end{array}$ & $\begin{array}{l}\text { Year of } \\
\text { A. planci } \\
\text { outbreak }\end{array}$ & $\begin{array}{l}\text { Date of } \\
\text { survey }\end{array}$ & $\begin{array}{c}\text { No. of } \\
\text { transects }\end{array}$ & $\begin{array}{l}\text { Total area } \\
\qquad\left(\mathrm{m}^{2}\right)\end{array}$ \\
\hline \multicolumn{8}{|c|}{ Unaffected reefis } \\
\hline Low Is. & $16^{\circ} 23^{\prime}$ & $145^{\circ} 34^{\prime}$ & ISP & - & $3 \operatorname{Mar} 87$ & 3 & 900 \\
\hline Hastings & $16^{\circ} 31^{\prime}$ & $146^{\circ} 01^{\prime}$ & OSP & - & 25 Jun 87 & 6 & 1800 \\
\hline Fitzroy Is. & $16^{\circ} 56^{\prime}$ & $146^{\circ} 00^{\prime}$ & ISF & - & 2 Mar 87 & 9 & 2700 \\
\hline N. Brook Is. & $18^{\circ} 09^{\prime}$ & $146^{\circ} 18^{\prime}$ & ISF & - & 22 Oct 87 & 9 & 2700 \\
\hline Normanby Is. & $17^{\circ} 13^{\prime}$ & $146^{\circ} 05^{\prime}$ & ISF & - & 28 Feb 87 & 9 & 2700 \\
\hline Davies. & $18^{\circ} 50^{\prime}$ & $147^{\circ} 39^{\prime}$ & MSP & - & 22 Jun 88 & 3 & 900 \\
\hline \multicolumn{8}{|l|}{ Affected reefs } \\
\hline Green Is. & $16^{\circ} 46^{\prime}$ & $145^{\circ} 58^{\prime}$ & ISP & $1979-81$ & 19 Feb 87 & 15 & 4500 \\
\hline Potter & $17^{\circ} 42^{\prime}$ & $146^{\circ} 53^{\prime}$ & OSP & 1983 & 26 Feb 87 & 9 & 2700 \\
\hline Beaver & $17^{\circ} 51^{\prime}$ & $146^{\circ} 29^{\prime}$ & MSP & $1982-83$ & 20 Jun 87 & 3 & 900 \\
\hline $\mathrm{Rib}$ & $18^{\circ} 29^{\prime}$ & $147^{\circ} 53^{\prime}$ & MSP & $1983-84$ & $19 \mathrm{Jan} 87$ & 3 & 900 \\
\hline John Brewer & $18^{\circ} 38^{\prime}$ & $147^{\circ} 04^{\prime}$ & MSP & $1983-85$ & $22 \operatorname{Sep} 86$ & 9 & 2700 \\
\hline Holbourne Is. & $19^{\circ} 44^{\prime}$ & $148^{\circ} 22^{\prime}$ & ISF & $1985-87$ & 1 Feb 87 & 9 & 2700 \\
\hline
\end{tabular}


Table 2. Composition of massive coral assemblage on reefs unaffected and affected by major Acanthaster planci population outbreaks, indicated by the percentages of colonies in different taxa

\begin{tabular}{|c|c|c|}
\hline \multirow[t]{2}{*}{ Coral taxa } & \multicolumn{2}{|c|}{$\%$ Colonies } \\
\hline & $\begin{array}{l}\text { Unaffected } \\
\text { reefs }\end{array}$ & $\begin{array}{l}\text { Affected } \\
\text { reefs }\end{array}$ \\
\hline Poritidae & 34 & 56 \\
\hline Faviidae & 40 & 31 \\
\hline Mussidae & 15 & 4 \\
\hline Other families & 11 & 9 \\
\hline Porites & 30 & 52 \\
\hline Favia & 11 & 9 \\
\hline Favites & 5 & 5 \\
\hline Goniastrea & 10 & 8 \\
\hline Lobophylia & 11 & 1 \\
\hline Symphyllia & 3 & 3 \\
\hline
\end{tabular}

Porites), faviids comprised $40 \%$ and mussids comprised $15 \%$. On affected reefs, poritids comprised $56 \%$ (52\% for Porites), faviids $31 \%$ and mussids only $4 \%$ (Table 2).

Overall, there were markedly fewer massive corals, irrespective of colony size or degree of damage, on the affected reefs than on the unaffected reefs, with the difference being significant for the total assemblage and for the families Faviidae and Mussidae but not for the Poritidae (Table 3). For corals with $<1 / 3$ colony damage there were significant differences between the 2 reef sets in numbers of colonies of all these major taxa (Table 3). The depauperate state of the entire assemblage, of the families Faviidae, Mussidae and Poritidae

Table 3. Mean numbers ha ${ }^{-1}$ (with standard errors) of massive corals on both reef sets and the percentages by which the means for affected reefs differ from those for unaffected reefs. Corals of families other than those named represented ca $10 \%$ only of the assemblage on both reef sets. (A) All corals, irrespective of colony size or damage $(B)$ corals with $<1 / 3$ damage

\begin{tabular}{|c|c|c|c|c|}
\hline & \multicolumn{2}{|c|}{ Mean numbers ha ${ }^{-1}$} & \multirow[t]{2}{*}{$\mathrm{p}$} & \multirow{2}{*}{$\begin{array}{c}\% \\
\text { Differ- } \\
\text { ence }\end{array}$} \\
\hline & $\begin{array}{l}\text { Unaffected } \\
\text { reefs }\end{array}$ & $\begin{array}{l}\text { Affected } \\
\text { reefs }\end{array}$ & & \\
\hline \multicolumn{5}{|l|}{ A } \\
\hline All massive corals & $4015(727)$ & $1471(103)$ & $\because$ & 63 \\
\hline Poritidae & $1369(475)$ & $824(238)$ & & 40 \\
\hline Faviidae & $1621(584)$ & $449(134)$ & - & 72 \\
\hline Mussidae & $606(280)$ & $63(43)$ & $\cdots$ & 90 \\
\hline \multicolumn{5}{|l|}{ B } \\
\hline All massive corals & $3454(791)$ & $727(209)$ & $\because$ & 79 \\
\hline Poritidae & $1060(379)$ & $382(117)$ & $\cdot$ & 64 \\
\hline Faviidae & 1462 (.505) & $195(69)$ & $\cdots$ & 87 \\
\hline Mussidae & $594(244)$ & $44(30)$ & $\cdots$ & 92 \\
\hline \multicolumn{5}{|c|}{$\begin{array}{l}\text { Significance of differences between reef sets (Wilcoxon } \\
\text { rank sum test): } \cdot p \leq 0.05 ; \cdots p \leq 0.01\end{array}$} \\
\hline
\end{tabular}

and of a representative genus, Favia, on the affected reefs is shown in Figs. 1 to 5. Two general trends are apparent from these figures: (1) there were substantially fewer corals in all 3 size classes on the affected reefs than on the unaffected reefs, the exception being poritid recruits $<10 \mathrm{~cm}$ in diameter, which were similar in numbers on both reef sets; (2) many of the surviving corals on affected reefs exhibited substantial colony damage. For corals with $<1 / 3$ colony damage, there were significantly fewer large colonies $(>10 \mathrm{~cm}$ diameter in most taxa on the affected reefs than on reefs unaffected by outbreaks (Table 4 ).

Approximately half the corals present on affected reefs had suffered partial mortality exceeding $1 / 3$ their colony surfaces (Figs. 1 to 5). Since badly damaged corals do not regrow over their own coralla (Hughes \& Jackson 1980, Done 1987), these colonies have been reduced to much smaller sizes. By contrast, most corals on unaffected reefs were intact or exhibited only low levels of colony damage, generally restricted to $<1 / 3$ colony surface area. The family Poritidae, composed predominantly of the genus Porites, exhibited comparitively greater levels of such background mortality than other taxa on unaffected reefs (Fig. 4).

\section{DISCUSSION}

Colonies of massive corals on reefs unaffected by Acanthaster planci outbreaks exhibited negligible background mortality, apart from that shown by representatives of the family Poritidae (Endean et al. 1989). Some of the partial mortality exhibited by Porites spp. had resulted from self-shading during colony growth (DeVantier \& Endean 1989). Interspecific interactions and sedimentation were probably responsible for much of the remaining partial mortality (L.M.D own obs.). By contrast, many of the surviving corals on reefs affected by $A$. planci outbreaks exhibited substantial colony damage, generally in excess of $1 / 3$ colony surface area and often exceeding $2 / 3$ of the original colony surface. Although most corals on the affected reefs had obviously suffered predation by $A$. planci during the recent outbreaks, as evidenced by typical starfish feeding scars, some of the damage could have been caused by other agencies. It was for this reason, and in the absence of detailed before, during and postoutbreak studies that massive coral communities on reefs that had been affected by $A$. planci outbreaks were compared with those on unaffected reefs. Allowance was thereby made for destruction of massive corals by agencies other than $A$. planci.

During the second recorded outbreak series in the $1980^{\prime}$ s, outbreaks were observed on reefs in the region (e.g. Green Island Reef) almost as soon as a coral cover 

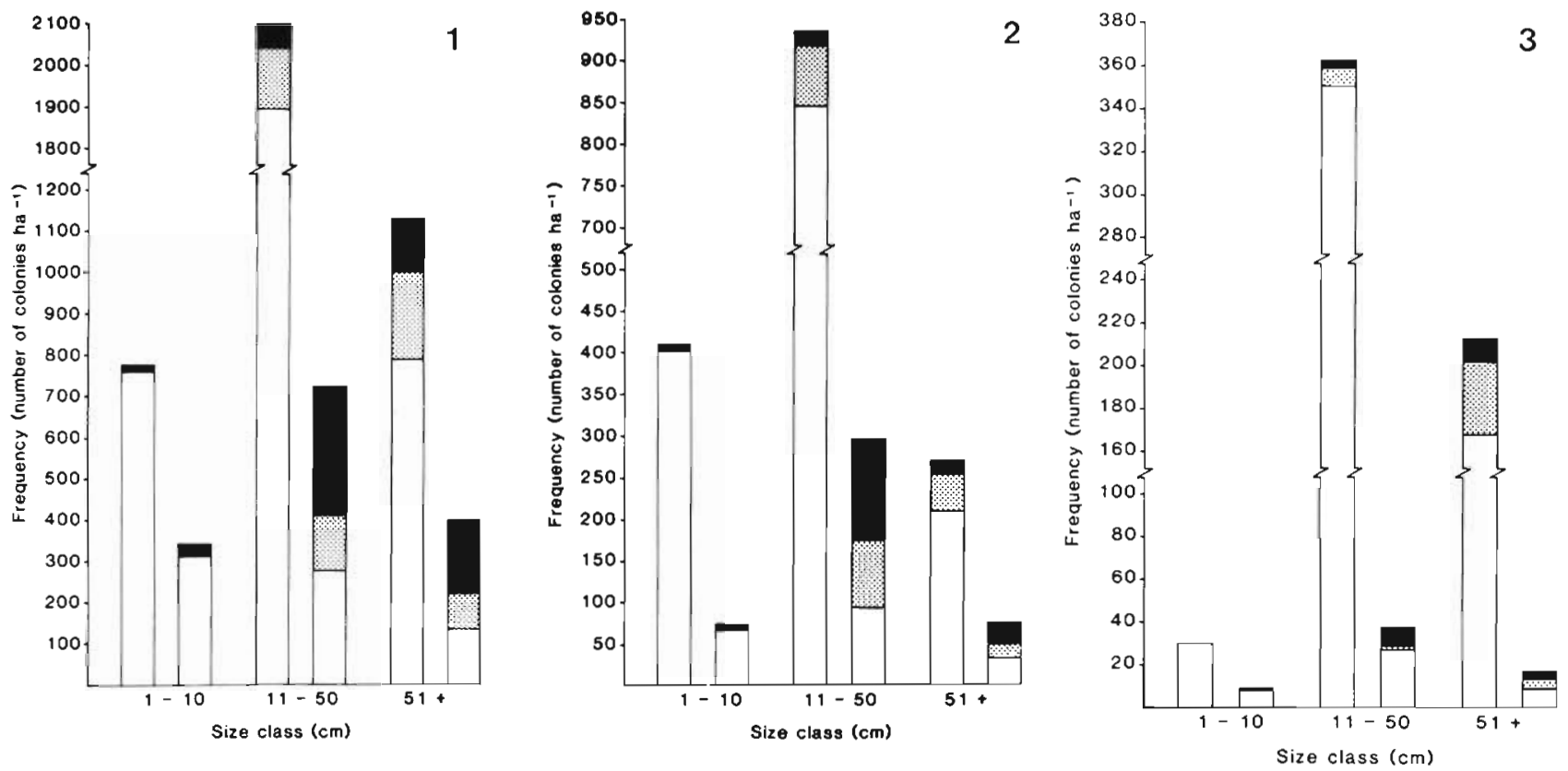

Figs. 1 to 5. Size and damage frequency distributions for massive corals sampled on 6 reefs unaffected by major Acanthaster planci population outbreaks (left-hand bars) and on 6 affected reefs (right-hand bars). Unshaded bars: colonies with $<1 / 3$ damage; stippling, with $1 / 3$ to $2 / 3$ damage; black, with $>2 / 3$ damage. Note breaks in vertical axes. Fig. 1: All massive corals; Fig. 2: $\overline{\text { family }}$ Faviidae; Fig. 3: family Mussidae; Fig. 4: family Poritidae; Fig. 5: genus Favia
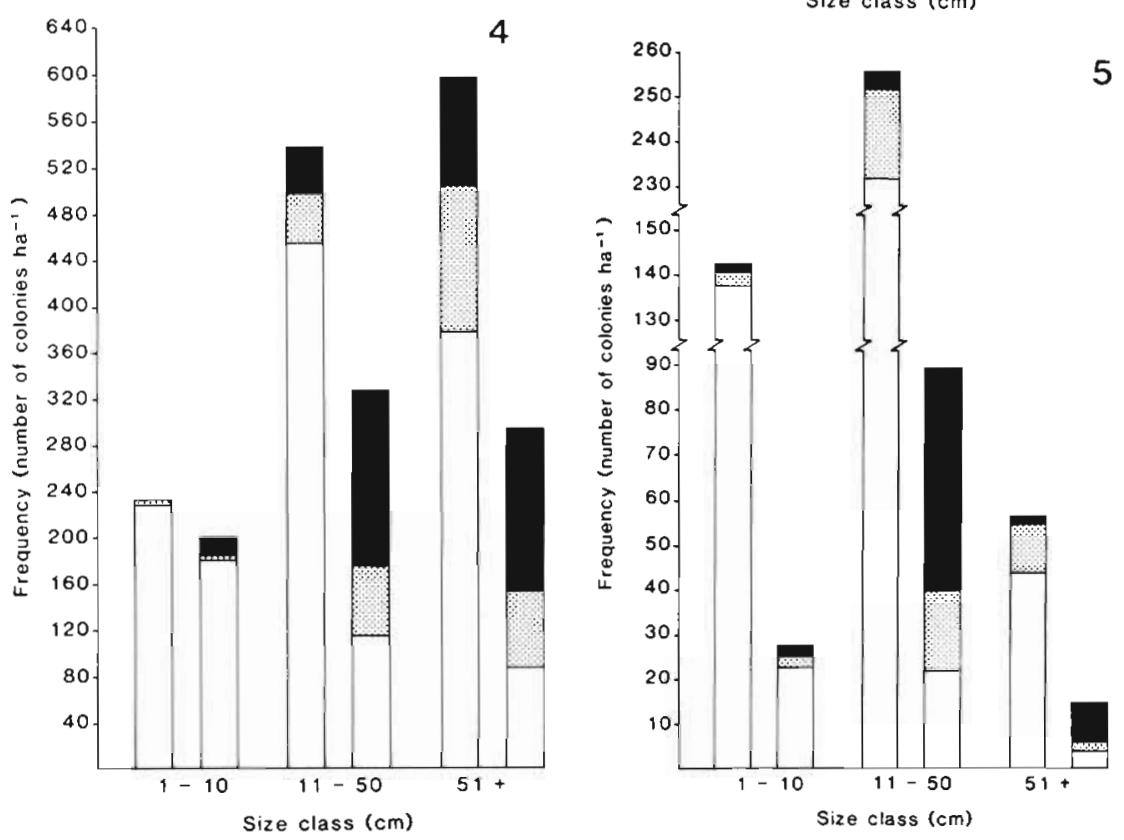

was reestablished. If reinfestation by Acanthaster planci continues to be coincident with recovery of a coral cover by fast-growing branching and plate-like corals, the massive coral assemblage cannot recover and will continue to be degraded, the complexity of the coral communities will be reduced and a state of impoverishment will ultimately result.

In this regard, the results of the present study are unequivocal. Reefs of the GBR that have been affected by major Acanthaster planci outbreaks since the 1960's carried assemblages of massive corals possessing only ca $1 / 3$ the colonies on nearby unaffected reefs. Moreover, the massive coral assemblages on affected reefs have lost most large (old) colonies, a situation that differs markedly from that on unaffected reefs. This trend was most marked for the Faviidae and Mussidae. Such effects were lessened for the Poritidae by the relatively faster growth rates of Porites spp. and their defence by inquilines from total predation by $A$. planci. Furthermore, approximately half the surviving massive corals on affected reefs have been reduced substantially in size (exhibiting damage of $>1 / 3$ their surface areas).

As well as the difference in the size (and age) structures of massive coral populations on affected reefs, the relative abundances of the taxa represented are differ- 
Table 4. Mean number ha- (with standard errors) of massive corals either intact or with only slight damage ( $<1 / 3$ surface area) in 3 size classes $(1$ to $10 \mathrm{~cm}$ diameter, 11 to $50 \mathrm{~cm}, 51+\mathrm{cm}$ ) on the 2 reef sets, and percentages by which the means for affected reefs (A) differ from those for unaffected reefs (U)

\begin{tabular}{|c|c|c|c|c|c|c|c|c|c|c|c|c|}
\hline \multirow[t]{2}{*}{ Coral taxa } & \multicolumn{4}{|c|}{ Diameter 1 to $10 \mathrm{~cm}$} & \multicolumn{4}{|c|}{ Diameter 11 to $50 \mathrm{~cm}$} & \multicolumn{4}{|c|}{ Diameter $51+\mathrm{cm}$} \\
\hline & $\mathrm{U}$ & $A$ & $\mathrm{p}$ & $\%$ & $\mathrm{U}$ & A & $\mathrm{p}$ & $\%$ & $\mathrm{U}$ & A & $\mathrm{p}$ & $\%$ \\
\hline All massive corals & $764(343)$ & $312(93)$ & & 59 & $1987(226)$ & $279(82)$ & $\cdots$ & 85 & $793(221)$ & $136(29)$ & $\cdot$ & 83 \\
\hline Poritidae & 228 (129) & $181(64)$ & & 28 & $455(161)$ & $115(32)$ & $\cdot$ & 75 & $378(89)$ & $87(21)$ & $\cdot \cdot$ & 77 \\
\hline Faviidae & $403(235)$ & $67(25)$ & & 83 & $848(215)$ & $94(33)$ & $\because$ & 89 & $211(55)$ & $34(12)$ & $\cdots$ & 84 \\
\hline Mussidae & $30(11)$ & $8(5)$ & $\cdot$ & 73 & $351(128)$ & $27(19)$ & $\cdot$ & 92 & $158(105)$ & $9(7)$ & $\cdot$ & 95 \\
\hline Porites & $215(129)$ & $176(66)$ & & 18 & $337(143)$ & $87(25)$ & $\cdot$ & 74 & $342(84)$ & $79(22)$ & $\cdot$ & 77 \\
\hline Favia & $138(88)$ & $23(8)$ & & 83 & $232(72)$ & $22(4)$ & $\cdot \cdot$ & 91 & $44(19)$ & $4(3)$ & $\cdot$ & 91 \\
\hline Favites & $47(25)$ & $8(3)$ & & 83 & $123(40)$ & $14(8)$ & $\cdot \cdot$ & 89 & $16(7)$ & $2(2)$ & & 88 \\
\hline Goniastrea & $151(81)$ & $27(11)$ & & 82 & $193(47)$ & $24(7)$ & $\cdots$ & 88 & $18(4)$ & $2(1)$ & $\cdots$ & 89 \\
\hline Lobophyllia & $15(6)$ & $4(3)$ & & 73 & $247(122)$ & $8(5)$ & $\cdots$ & 97 & $128(95)$ & $1(1)$ & $\cdot$ & 99 \\
\hline Smphyllia & $6(2)$ & $1(1)$ & & 83 & $60(15)$ & $18(13)$ & $\cdot$ & 70 & $34(12)$ & $8(6)$ & $\cdot$ & 76 \\
\hline
\end{tabular}

ent. Faviidae and Mussidae were poorly represented on affected reefs whereas collectively they dominated the taxa on unaffected reefs (Table 2). By contrast, colonies of Porites spp. constitute more than half the assemblage on affected reefs but less than $1 / 3$ of the total colonies on unaffected reefs. Thus, as well as an overall depletion in numbers of massive coral colonies, marked changes in the proportion of colonies carrying extensive areas of damage, in the size (age) structure of massive coral communities and in the relative abundances of massive corals of different taxa following A. planci outbreaks are already in evidence.

At least some massive coral species have long prereproductive periods, of the order of 5 to 8 yr (Kojis \& Quinn 1985, Babcock 1989). On attaining reproductive age, such small colonies produce relatively few gametes in comparison with large colonies. Thus the reduction in numbers and sizes of corals on outbreakaffected reefs is likely to be compounded in the longer term by a marked reduction in reproductive output, further slowing recovery. Because of the geographical extent of the devastated region (in excess of 3 degrees of latitude, Johnson et al. 1989) and the probable larval connectedness of reefs of the region (Oliver \& Willis 1987), it is possible that sexually-produced recruits for initiation of recovery are becoming scarce. If recruitment and survivorship of remnants between outbreaks remain low (Babcock 1989, Endean et al. 1989, Fisk \& Harriott 1990), many taxa of the assemblage might be expected to become extinct locally. For example, corals of the family Mussidae on affected reefs were represented by only $10 \%$ of the numbers found on reefs unaffected by the outbreaks (Table 3). Even despite the relatively greater resistance of Porites spp. to Acanthaster planci predation compared with the susceptibility of other massive corals (Endean et al, 1989), some communities of Porites spp. could withstand as few as 2 or 3 further $A$. planci outbreaks comparable with those of the 1980's under modelling conditions of failed recruitment and high background mortality (Done 1988, Done et al. 1989). The capacity of the massive coral assemblage as a whole to recover from further $A$. planci outbreaks is considerably less than that of Porites. For many taxa of massive corals, growth rates are only half those of Porites spp. Mortality of massive coral colonies generally has been much greater than that suffered by Porites spp. (Endean et al. 1989), and the mortality of surviving remnants of massive corals can be high. For example, colony remnants $<10 \mathrm{~cm}$ in diameter on one reef had suffered $50 \%$ mortality 1 yr after an $A$. planci outbreak through overgrowth by other sessile organisms (Endean et al. 1989). In view of these factors it can be predicted that massive coral communities are unlikely to withstand even the 2 or 3 further A. planci outbreaks required for local extinction of Porites spp. in the worst case scenario presented by Done (1988).

The observed interval between outbreak episodes on reefs devastated twice by the starfish is ca $15 \mathrm{yr}$. It is unlikely that further outbreaks could occur on these reefs prior to their acquisition of a cover of fast-growing corals and there would appear to be no a priori reason why outbreaks should occur at intervals much longer than the time taken for reefs to acquire such a coral cover. Although some authors link restoration of coral cover per se with recovery following Acanthaster planci outbreaks (Walbran et al. 1989), complete recovery requires reestablishment of the abundances and size distributions of the constituent species (Endean et al. 1989). It will be determined by the persistence of unaffected colonies, by the survivorship and growth of colony remnants and by the level of recruitment of new colonies. Comparison of colony 
numbers, of the levels of damage exhibited, and of the size structures of massive coral assemblages found on both affected and unaffected reefs, taken in conjunction with the slow growth rates of many massive coral species of ca 0.5 to $1.0 \mathrm{~cm}$ radially per year (Buddemeir \& Kinzie 1976, Babcock 1985, pers. obs.) indicates that 10 to $15 \mathrm{yr}$ are clearly insufficient for recovery of the massive coral assemblage. Indeed, massive corals growing at $0.5 \mathrm{~cm}$ radially per year which colonized reefs immediately following the 1960's outbreaks would have attained diameters $<15 \mathrm{~cm}$ in the period prior to the second outbreak series. Colonies of such sizes are highly susceptible to being killed outright in a single $A$. planci predation episode. The time scale on which the continuing degradation of the GBR must be viewed is the ecological one based on the longevities of massive corals. Many colonies of massive coral species in the assemblage persist for decades to centuries. Some of the colonies measured were several metres in diameter and are hundreds of years old.

The data presented support the view advanced by Endean \& Cameron (1985) that the longterm impoverishment of reefs whose hard coral cover has been devastated by Acanthaster planci twice in the past $20 \mathrm{yr}$ is now probable. The basic structure of the communities will be lost as a result of the destruction of massive corals. Further loss of massive corals during $A$. planci outbreaks occurring at $15 \mathrm{yr}$ intervals may lead to the local extinction of such corals with the possible exception of Diploastrea heliopora (Cameron et al. in press) and some Porites spp. Our prognosis for reefs in the central region of the GBR, in the absence of effective control measures, is that there will be continued outbreaks of $A$. planci following restoration of coral cover by fast-growing, opportunistic species, resulting in a gradual breakdown in the structure of the complex coral communities on these reefs. The communities of massive corals will lose adult colonies and will become dominated progressively by prereproductive recruits, provided sufficient sexual reproduction occurs to supply the affected reefs with propagules. In the intervals of approximately $15 \mathrm{yr}$ between successive $A$. planci outbreaks the reefs will probably carry covers consisting predominantly of algae for 8 to $10 \mathrm{yr}$ followed by branching and plate corals for 5 to $7 \mathrm{yr}$.

Repeated outbreaks of the intensity of those of the past 20 yr could not have occurred in the century prior to the 1960's on reefs of the central third of the GBR, otherwise, the reefs would not carry the numbers and size structures of massive corals observed during this study. Indeed, were outbreaks of the intensity of those of the past 20 yr regular or cyclical features of coral reef ecosystems prior to the $1950^{\prime}$ s, the complex assemblage of long-lived massive corals we have described could not exist.
The information presented is consistent with the view that the outbreaks on the GBR are novel events, peculiar to the latter half of the 20th century and coincident with large-scale human activities on the GBR, rather than integral features of reef ecology in the region. One hypothesis that has been proposed to account for these outbreaks is that of removal of predators of the starfish, principally piscine and molluscan predators of juvenile and sub-adult starfish (Endean 1973, 1977, McCallum 1987, McCallum et al. 1989, Ormond et al. 1990). This hypothesis still requires testing, even though it has been proposed in various forms for almost $20 \mathrm{yr}$.

Acknowledgements. We thank H. I. McCallum for statistical advice, L. Pryor for drawing the figures and the Australian Institute of Marine Science for use of facilities. We thank R. H. Bradbury, T. J. Done, H. I. McCallum and P. J. Moran for reviewing an earlier version of the manuscript. This work was funded by the AIMS COTSAC program and the University of Queensland.

\section{LITERATURE CITED}

Babcock, R. C. (1985). Growth and mortality in juvenile corals (Goniastrea, Platygyra and Acropora): the first year. Proc. 5th Int. Coral Reef Congr. 4: 355-360

Babcock, R. C. (1989). Age-structure, survivorship and fecundity in populations of massive corals. Proc. 6th Int Coral Reef Symp. 2: 625-633

Buddemeir, R. W. Kinzie, R. A. (1976). Coral growth. Oceanogr. mar. Biol. A. Rev. 14: 183-225

Cameron, A. M., Endean, R. (1985). Do long-lived species structure coral reef ecosystems? Proc. 5th Int. Coral Reef Congr. 6: 211-215

Cameron, A. M., Endean, R., DeVantier, L. M. (in press). The effects of Acanthaster planci predation on populations of two species of massive coral. Hydrobiologia

DeVantier, L. M., Endean, R. (1988). The scallop Pedum spondyloideum mitigates the effects of Acanthaster planci predation on the host coral Porites: host defence facilitated by exaptation? Mar. Ecol. Prog. Ser. 47: 293-301

DeVantier, L. M., Endean, R. (1989). Observations of colony fission following ledge formation in massive reef corals of the genus Porites. Mar. Ecol. Prog. Ser. 58: 191-195

DeVantier, L. M., Reichelt, R. E., Bradbury, R. H. (1986). Does Spirobranchus giganteus protect host Porites from predation by Acanthaster planci: predator pressure as a mechanism of coevolution? Mar. Ecol. Prog. Ser. 32: 307-310

Done, T. J. (1985). Effects of two Acanthaster outbreaks on coral community structure the meaning of devastation. Proc. 5th Int. Coral Reef Congr. 5: 315-320

Done, T. J. (1987). Simulation of the effects of Acanthaster planci on the population structure of massive corals in the genus Porites: evidence of population resilience? Coral Reefs 6: 75-90

Done, T. J. (1988). Simulation of recovery of pre-disturbance size structure in populations of Porites spp. damaged by the crown of thorns starfish Acanthaster planci. Mar. Biol. 100: 51-61

Done, T. J., Osborne, K., Navin, K. F. (1989). Recovery of 
corals post-Acanthaster: progress and prospects. Proc. 6th Int. Coral Reef Symp. 2: 137-142

Druffel, E. M. (1982). Banded corals: changes in oceanic carbon-14 during the Little Ice Age. Science 218: 13-19

Endean, R. (1973). Population explosions of Acanthaster planci and associated destruction of hermatypic corals in the Indo-West Pacific region. In: Jones, O. A.. Endean, R. (eds.) Biology and geology of coral reefs, Vol. II, Biology I. Academic Press, New York, p. 389-438

Endean, R. (1976). Destruction and recovery of coral reef communities. In: Jones, O. A., Endean, R. (eds.) Biology and geology of coral reefs, Vol. III, Biology 2. Academic Press, New York, p. 215-254

Endean, R. (1977). Acanthaster planci infestations on reefs of the Great Barrier Reef. Proc. 3rd Int. Coral Reef Symp. 1: 185-191

Endean, R., Cameron, A. M. (1985). Ecocatastrophe on the Great Barrier Reef. Proc. 5th Int. Coral Reef Congr. 5: 309-314

Endean, R., Cameron, A. M. (1990). Trends and new perspectives in coral reef ecology. In: Dubinsky, Z. (ed.) Ecosystems of the world, Vol. 25, Coral Reefs. Elsevier, Amsterdam, p. 469-492

Endean, R., Cameron, A. M., DeVantier, L. M. (1989). Acanthaster planci predation on massive corals: the myth of rapid recovery of devastated reefs. Proc. 6th Int. Coral Reef Symp. 2: 143-148

Fisk, D. A., Harriott, V J. (1990). Spatial and temporal variation in coral recruitment on the Great Barrier Reef: implications for dispersal hypotheses. Mar. Biol. 107: $485-490$

Fisk, D. A., Harriott. V J., Pearson, R. G. (1989). The history and status of crown-of-thorns starfish and corals at Green Island Reef, Great Barrier Reef. Proc. 6th Int. Coral Reef Symp. 2: 149-155

Hughes, T. P., Jackson, J. B. C. (1980). Do corals lie about their age? Some demographic consequences of partial mortality, fission, and fusion. Science 209: 713-715

Isdale, P. J. (1984). Fluorescent bands in massive corals record centuries of coastal rainfall. Nature, Lond. 310: 578-579

Johnson, D. B., Bass, D. K., Miller-Smith, B. A., Moran, P. J., Mundy, C. N., Speare, P. J. (1989). Outbreaks of the crown-of-thorns starfish (Acanthaster planci) on the Great Barrier Reef: results of surveys 1986-1988. Proc. 6th Int. Coral Reef Symp. 2: 165-169

Keesing, J. K., Bradbury, R. H., DeVantier, L. M., Riddle, M. J., De'Ath, G. (in press). The geological evidence for recur-

This article was submitted to the editor ring outbreaks of the crown-of-thorns starfish: a reassessment from an ecological perspective. Coral Reefs

Kojis, B. L., Quinn, N. J. (1985). Puberty in Goniastrea favulus age or size limited? Proc. 5th Int. Coral Reef Congr. 4: 289-293

Lehmann, E. L. (1975). Nonparametrics: statistical methods based on ranks. Holden-Day, San Francisco

McCallum, H. I. (1987). Predator regulation of Acanthaster planci. J. theoret. Biol. 127: 207-220

McCallum, H. I., Endean, R., Cameron, A. M. (1989). Sublethal damage to Acanthaster planci as an index of predation pressure. Mar. Ecol. Prog. Ser. 56: 29-36

Moran, P. J. (1986). The Acanthaster phenomenon. Oceanogr. mar. Biol. A. Rev. 24: 379-480

Moran, P. J., Bradbury, R. H. (1989). The crown-of-thorns starfish controversy. Search 20:3-6

Moran, P. J., Bradbury, R. H., Reichelt, R. E. (1988). Distribution of recent outbreaks of the crown-of-thorns starfish (Acanthaster plancl) along the Great Barrier Reef: 1985-1986. Coral Reefs 7: 125-137

Moran, P. J., Reichelt, R. E., Bradbury, R. H. (1986). An assessment of the geological evidence for previous Acanthaster outbreaks. Coral Reefs 4: 235-238

Nozaki, Y., Rye, D. M., Turekian, K. K., Dodge, R. E. (1978). A 200 year record of carbon-13 and carbon-14 variations in a Bermuda coral. Geophys. Res. Lett. 5: 825-828

Oliver, J. K., Willis, B. J. (1987). Coral spawn slicks in the Great Barrier Reef: preliminary observations. Mar. Biol. 94: 521-530

Ormond, R., Bradbury, R. H., Bainbridge, S., Fabricius, K., Keesing, J. K., DeVantier, L. M., Medlay, P., Steven, A. D. L. (1990). Test of a model for regulation of crown-of-thorns starfish by fish predators. In: Bradbury, R. H. (ed.) Acanthaster and the coral reef: a theoretical perspective. Lecture notes in bio-mathematics. Springer-Verlag, New York, p. 189-207

Pearson, R. G. (1981). Recovery and recolonization of coral reefs. Mar. Ecol. Prog. Ser. 4: 105-122

Potts, D. C., Done, T J., Isdale, P. J., Fisk, D. A. (1985). Dominance of a coral community by the genus Porites (Scleractinia). Mar. Ecol. Prog. Ser. 23: 79-84

Veron, J. E. N. (1986). Corals of Australia and the Indo-Pacific. Angus and Robertson, Sydney, Australia

Walbran, P. D., Henderson, R. A., Jull, A. J. T., Head, M. J. (1989). Evidence from sediments of long-term Acanthaster planci predation on corals of the Great Barrier Reef. Science 245: $84.7-850$

Manuscript first received: January 16, 1991

Revised version accepted: June 7, 1991 